\title{
Cinemateca Brasileira: o sequestro e a destruição de nossa memória audiovisual
}

\author{
Cinemateca Brasileira: the kidnapping and destruction of our audiovisual \\ memory
}

\section{Cinemateca Brasileira: el secuestro y la destrucción de nuestra memoria audiovisual}

\author{
Eduardo Morettin ${ }^{1, a}$ \\ eduardomorettin@usp.br | https://orcid.org/oooo-0002-1207-4969 \\ ${ }^{1}$ Universidade de São Paulo, Escola de Comunicações e Artes. São Paulo, SP, Brasil. \\ a Doutorado em Artes pela Universidade de São Paulo.
}

\section{RESUMO}

Esta nota trata da crise que atingiu a Cinemateca Brasileira desde 2019, historiando os seus motivos e avaliando os danos provocados pelas últimas ações governamentais. O empenho em descrever neste trabalho as atividades da Cinemateca Brasileira e o que ela representa para toda a sociedade aponta para a convicção de que, mesmo em meio à gravidade do quadro atual, a instituição sobreviverá. Não será por vontade do atual governo ou por virtude de moto-contínuo, mas pela reação da nossa sociedade civil e da Justiça de nosso país ao conjunto de desacertos que a atingiu em cheio.

Palavras-chave: Cinemateca Brasileira; História do cinema brasileiro; Políticas culturais; Preservação; Memória.

\begin{abstract}
This note deals with the crisis that has been affecting the Cinemateca Brasileira since 2019, revealing the history of the reasons for that turn of events and evaluating the damages brought about by the last governmental actions relating to the institution. The endeavour to describe in this work the activities developed by Cinemateca Brasileira and what it represents to society as a whole points out a conviction that in spite of the gravity of current situation the institution will survive. This might not be true by the will of the current government or by virtue of perpetual motion, but this might happen by reaction of our civil society and of the Courts of Justice of our country against a set of faults which affected it completely.
\end{abstract}

Keywords: Cinemateca Brasileira; History of Brazilian cinema; Cultural Policies; Preservation; Memory. 


\section{RESUMEN}

Esta nota trata de la crisis que afecta a la Cinemateca Brasileira desde 2019, historiando los motivos que la ocasionan y evaluando los daños provocados por las últimas acciones gubernamentales relacionadas con la institución. El esfuerzo por describir en este trabajo las actividades que la Cinemateca Brasileira desarrolla y lo que ella representa para la sociedad en su conjunto apunta a la convicción de que a pesar de la gravedad de la situación actual, la institución sobrevivirá. Puede que esto no sea así por voluntad del actual gobierno o en virtud del móvil perpetuo, pero sí puede suceder por reacción de nuestra sociedad civil y de los Tribunales de Justicia de nuestro país ante un conjunto de desaciertos que la afectaron por completo.

Palabras clave: Cinemateca Brasileira; Historia del cine brasileño; Políticas culturales; Preservación; Memoria.

Contribuição dos autores: o autor é responsável integralmente pelo texto.

Declaração de conflito de interesses: não há.

Fontes de financiamento: Conselho Nacional de Desenvolvimento Científico e Tecnológico.

Considerações éticas: não há.

Agradecimentos/Contribuições adicionais: sem o apoio e a aquisição dos documentos fornecidos por Almir Almas, Carlos Augusto Calil e Maria Dora Mourão as reflexões presentes neste texto não seriam possíveis.

Histórico do artigo: submetido: 24 ago. 2021 | aceito: 24 ago. 2021 | publicado: 31 ago. 2021.

Apresentação anterior: este texto retoma e amplia, à luz dos fatos recentes, artigo escrito pelo autor em 2020 no Jornal da USP (MORETTIN, 2020).

Licença CC BY-NC atribuição não comercial. Com essa licença é permitido acessar, baixar (download), copiar, imprimir, compartilhar, reutilizar e distribuir os artigos, desde que para uso não comercial e com a citação da fonte, conferindo os devidos créditos de autoria e menção à Reciis. Nesses casos, nenhuma permissão é necessária por parte dos autores ou dos editores. 
“O projeto do governo é exterminar-nos: artistas, intelectuais, cineastas, professores... que somos o 'marxismo cultural'..." Jean-Claude Bernardet (2019)

"sempre haverá um papel a ser cumprido pelo intelectual que resolva sair da perplexidade e se recuse a cair no desespero" Paulo Emilio Salles Gomes, 1973 (2021)

A Cinemateca Brasileira é a instituição federal responsável pela documentação, preservação e difusão de nossa memória audiovisual. Criada por iniciativa de Paulo Emilio Salles Gomes em 1946, ela armazena o que restou do acervo de filmes brasileiros, bem como a coleção de telenovelas e telereportagens da TV Tupi, além de equipamentos cinematográficos e milhares de documentos, como cartazes, roteiros, artigos de jornal, correspondências, livros, fotografias entre outros. No que diz respeito ao arquivo fílmico, é um dos maiores da América Latina, composto por 30 mil títulos em 250 mil rolos de películas armazenados em seus vinte laboratórios climatizados e com controle de umidade. Tanto no Brasil como no exterior, inúmeros documentários e pesquisas, acadêmicas ou não, produzidos com material arquivístico somente puderam passar a existir em virtude do amplo e bem organizado acervo da Cinemateca Brasileira. O interesse por tudo aquilo que envolve a cultura cinematográfica é fomentado a partir de cursos, mostras e sessões organizados com apurado critério nas duas salas de projeção abarcadas com os melhores equipamentos e mais avançada estrutura que há para o setor. Tudo isso somente é possível em função da existência de um corpo de técnicos capacitados para atuar naquilo que se configura razão de ser da instituição: preservação, restauração e difusão. A Cinemateca é, portanto, instituição viva, aberta à riqueza, pluralidade e diversidade que caracterizam e constituem a produção cultural e cinematográfica do Brasil.

O empenho em descrever neste trabalho as atividades da Cinemateca Brasileira e o que ela representa para toda sociedade reforça a convicção de que, mesmo em meio à gravidade do quadro atual, a instituição sobreviverá. Não será por vontade do atual governo ou por virtude de moto-contínuo, mas pela reação da nossa sociedade civil e da Justiça de nosso país ao conjunto de desacertos que a atingiu em cheio. O quadro crítico da Cinemateca, instaurado em 2020, é exemplo, infelizmente, do modus operandi característico do governo Bolsonaro em relação aos valores culturais, que se pauta pelo esgotamento, destruição e asfixia de cada uma das instituições que estão sob sua alçada.

Em 7 de agosto de 2020, a Associação de Comunicação Educativa Roquette Pinto (Acerp), organização social responsável pela administração da Cinemateca Brasileira desde $2018^{1}$, passou as chaves da instituição para o representante da Secretaria do Audiovisual. Esse fato ilustrou a disposição geral para com o setor. Em primeiro lugar, cabe observar que são sempre os adjuntos, substitutos e representantes dos órgãos federais que respondem pelos titulares nos momentos em que a sua presença é requerida - sinal já temerário do frágil compromisso com as eventuais ações acordadas em reuniões com os interessados em resolver ou encaminhar soluções. Por exemplo, na sessão virtual da Câmara dos Deputados, coordenada pela deputada federal Jandira Feghali, ocorrida no dia 30 de julho de 2020 e intitulada 'A crise na Cinemateca Brasileira': mesmo diante de soluções urgentes, não compareceram nem o ministro do Turismo e muito

1 Explicarei à frente os motivos que levaram a Cinemateca Brasileira ser administrada por um organismo social sem fins lucrativos. 
menos o responsável pela Secretaria Especial da Cultura - secretaria e ministério ao qual se subordinam a Cinemateca - mas seus assessores, que não acompanharam até o final do evento².

Fato imensamente mais grave foi a presença, amplamente noticiada pelos diferentes meios de comunicação, de viaturas da Polícia Federal e de seus agentes armados com metralhadoras a fim de 'garantir' que a 'reintegração de posse’ fosse concluída. Pela primeira vez em sua história, a ameaça de uso da violência pairou no espaço o qual é dedicado à preservação, restauração e difusão de nossa memória audiovisual.

É preciso aqui abrir um breve parêntesis para explicar que a Cinemateca já vinha agonizando desde 2013, depois de ter experimentado seu apogeu entre 2008 e 2012 ${ }^{3}$. Em janeiro de 2013, o Ministério da Cultura, posteriormente extinto pelo governo Bolsonaro em janeiro de 2019, afasta seus dirigentes e interrompe o aporte de recursos dados à Sociedade de Amigos da Cinemateca (SAC), parceira da instituição desde o momento de sua criação em $1962^{4}$. Além da interrupção dos trabalhos em virtude da demissão de técnicos contratados pela SAC para cumprir diferentes atividades fins, novo regimento é publicado, enfraquecendo-a do ponto de vista institucional. Decorrente desta situação de abandono, em fevereiro de 2016 ocorre o quarto incêndio sofrido em sua história, com a perda de mais de mil rolos de filmes em nitrato de celulose. Esta perda levou o Ministério da Cultura, já sob o governo de Michel Temer, a coordenar o processo que resultou, alguns meses depois, na publicação de edital público para que uma entidade sem fins lucrativos administrasse as instalações e o acervo da Cinemateca - edital vencido pela Acerp naquele mesmo ano.

Fechado o parêntesis, volto ao imbróglio Acerp e governo federal. Antes de mais nada, é importante ressaltar que a Acerp não teve seu contrato interrompido com o governo federal por suposto vínculo ao 'marxismo cultural's. O único acerto de sua gestão foi o de manter, mesmo que em número reduzido, as trabalhadoras e os trabalhadores que continuaram, com esforço e dedicação, as diversas e complexas frentes de trabalho $0^{6}$. Já dentre os desacertos estão a substituição do logotipo criado, em 1954, por Alexandre Wallner, ato simbólico que representa a ruptura com o passado, que, logo em seguida, foi acompanhado por outro desacerto ainda mais concreto e nocivo: a não convocação do Conselho Consultivo - órgão responsável pela observância dos princípios que regem a Cinemateca e, como indicado em sua denominação, instância a ser consultada no momento da escolha de um novo diretor. Por meio de notificação extrajudicial ao então ministro da Cultura, em setembro de 2018, Carlos Augusto Calil, incansável defensor da Cinemateca e do cinema brasileiro, e a escritora Lygia Fagundes Telles já denunciavam o desrespeito às salvaguardas responsáveis por garantir a autonomia técnica, administrativa e financeira da instituição. Estabelecidas juridicamente durante a incorporação da Fundação Cinemateca Brasileira ao Estado, em 1984, por meio da Fundação Nacional Pró-Memória, essas salvaguardas foram criadas justamente para impedir o

\footnotetext{
2 Em 12 de abril de 2021, nova sessão online foi convocada pela mesma deputada a fim de cobrar do governo respostas e ações, dado que já se passavam oito meses sem que nenhuma das promessas feitas até então fossem cumpridas. No vídeo (COMISSÃO..., [2021]), em 2:35:17, o representante do governo federal afirmava que em 45 dias, ou seja, em maio deste ano, a sociedade civil poderia esperar encaminhamentos concretos ao problema enfrentado pela Cinemateca. Como se pode constatar, tratava-se de mais uma das inúmeras promessas não cumpridas.
}

3 Fato que pode ser constatado pela leitura dos relatórios de atividades do período, disponíveis do site da Cinemateca Brasileira ([2018?]).

4 Baseio-me aqui em texto de Carlos Augusto Calil (2021) sobre a história da Cinemateca Brasileira.

5 Como se sabe, esse termo é empregado pela extrema direita, no Brasil e nos Estados Unidos, para se referir à 'guerra cultural' que deve ser empreendida pelo governo. Seu entendimento é de que as universidades e instituições culturais públicas foram ocupadas por representantes da esquerda. Por isso, cabe sua eliminação. Significativo deste processo é o que se passa com a Fundação Cultural Palmares, órgão federal criado em 1988 para promover e preservar os valores históricos e culturais da comunidade afro-brasileira. $\mathrm{O}$ atual presidente da instituição anunciou em junho passado o expurgo do acervo da biblioteca de livros considerados de esquerda e "de obras pautadas pela revolução sexual” (FUNDAÇÃO CULTURAL PALMARES, 2021, p. 8). Dentre os livros a princípio excluídos, O Capital, de Karl Marx, e Bandidos, de Eric Hobsbawn.

6 Até 2013 o corpo técnico da Cinemateca Brasileira era composto por mais de 120 trabalhadores. No momento do fechamento da instituição, em agosto de 2020, o total era de 62. 
desvirtuamento das funções precípuas, zelando, assim, pelo seu bom funcionamento, e impedindo, por exemplo, que o acervo saísse da cidade de São Paulo7.

Tiago Batista, diretor do centro de conservação da Cinemateca Portuguesa, comentou a propósito de um vídeo postado em agosto de 2019 nas redes sociais: "Coisas muito assustadoras que se estão a passar na Cinemateca Brasileira...”. O curta de cinco minutos tinha como abertura a apresentação de um deputado estadual em um gesto de continência, tendo ao seu lado o então superintendente da Acerp e dois assessores, sendo um deles um militar que passa a discorrer, sobre o projeto de uma mostra de filmes sobre o Exército - proposta que não se efetivou, pois, como sabemos, o forte deste governo não é realizar e construir. $\mathrm{O}$ vídeo infame e, de fato, assustador, termina com o lema patriótico-religioso do atual governo que nos castiga desde o seu início.

Com militares e políticos de orientação conservadora circulando pela instituição, a Acerp estava, portanto, aparelhada - aparelhamento que vemos em muitas instituições culturais em âmbito federal e as quais são administradas por pessoas absolutamente despreparadas para o exercício da função pública.

O alinhamento 'ideológico’ não impediu, porém, que o contrato de gestão mantido pela Acerp desde 2015 com o Ministério da Educação fosse renovado ao final de 2019. Para o governo, o contrato da Acerp para a administração da Cinemateca, efetivado por meio de um aditivo ao contrato principal assinado, então, com o Ministério da Educação e o Ministério da Cidadania ${ }^{8}$, perdia sua validade ao final desse período. A partir dessa medida, os repasses de recursos deveriam, assim, ser interrompidos - o que ocorreu já no início de 2020.

Os motivos da cizânia nas hostes governistas são obscuros - como tudo o que povoa as mentes dos que hoje ocupam o Palácio da Alvorada e a sede dos edifícios ministeriais - mas as disputas entre os grupos que estão no poder fizeram as suas vítimas: a Cinemateca Brasileira, suas trabalhadoras e seus trabalhadores. Os compromissos financeiros junto aos fornecedores e funcionários pararam de ser cumpridos desde abril de 2020. Em meio à pandemia, mais de sessenta funcionários e suas famílias ficaram desempregadas.

Com as chaves da instituição desde agosto do ano passado, a Secretaria Especial da Cultura e o Ministério do Turismo se comprometeram a lançar edital de chamamento a fim de selecionar uma nova associação para a administração da Cinemateca - lançamento que ocorreu apenas no dia 30 de julho deste ano, um dia após o incêndio que atingiu uma das sedes da instituição em mais um ato de despreparo do governo federal, sem deixar respostas diante do ocorrido e sem querer assumir a culpa pela omissão com a qual vem tratando o caso.

Desde então, a Cinemateca abriga em suas dependências apenas funcionários que cuidam da chamada manutenção predial: jardineiros, seguranças, bombeiros etc. Em vista disso, o site do Banco de Conteúdos Culturais (BCC), no qual era disponibilizado ao público todo conteúdo que havia sido digitalizado, como cartazes, roteiros, filmes dos mais variados, do cinema silencioso às obras de Glauber Rocha, está fora do ar desde outubro de 2020. Um blecaute no bairro em que se situa a Cinemateca provocou a queda de vários sistemas, dentre eles o que alimentava o BCC. Como não há nenhum técnico especializado situado na instituição, o sistema não é religado e o site permanece inacessível. É de se imaginar, portanto, os riscos enfrentados pelo acervo documental e cinematográfico.

O Ministério Público Federal (MPF) também se posicionou contra essa situação e moveu bem fundamentada ação civil contra a Secretaria Especial da Cultura por omissão, tendo em vista que a situação da Cinemateca era e é de abandono. Na ação, o MPF solicitava a assinatura de contrato emergencial com

\footnotetext{
7 Este boato circulou em julho de 2020, em meio à troca de responsáveis pela Secretaria Especial da Cultura (SEC), órgão vinculado hoje ao Ministério do Turismo, como já disse, vínculo indicativo de quanto o atual governo se preocupa com a cultura.

8 O caos administrativo causado pela extinção do Ministério da Cultura pelo governo Bolsonaro e o repasse das responsabilidades da Cinemateca para outros dois ministérios, o da Cidadania e depois o do Turismo, também contribuíram para ineficiência de todo e qualquer processo administrativo.
} 
nova organização social sem fins lucrativos e o estabelecimento do Conselho Consultivo. Infelizmente, além de ser questionada pela Advocacia Geral da União em agravo de final de julho de 2020, a ação foi indeferida no ano passado pela juíza federal que arbitrou o processo, avaliando que as demandas eram desprovidas de sentido9. O amplo movimento de ideias não foi o suficiente para que as duas instâncias compreendessem de fato a real dimensão do problema. Para elas, a assinatura dos contratos emergências de limpeza, fornecimento de água e energia elétrica, vigilância etc., serviços certamente fundamentais e sem os quais nenhuma instituição pode abrir as suas portas, sinalizam que a preservação do acervo está garantida. Desconhece-se tanto o que está implicado nas tarefas do dia a dia dos arquivos fílmicos quanto a necessidade de técnicos especializados, com conhecimento e experiência, para lidar com as especificidades dos acervos. O MPF continua atuante, cobrando da Secretaria Especial da Cultura ações e responsabilidades.

Desde o início de 2020 a Cinemateca Brasileira foi notícia em diversos programas jornalísticos na televisão, foi motivo de posts nas mídias sociais e assunto de podcasts no Brasil. Mesmo que o assunto seja a crise, não deixa de ser alentador que as questões da preservação sejam disseminadas pela sociedade brasileira, em boa parte conduzidas pela Associação Brasileira de Preservação Audiovisual (ABPA). O manifesto ‘A Cinemateca Brasileira pede socorro' conta hoje com mais de 19 mil assinaturas, entre intelectuais, artistas, cineastas, associações nacionais e internacionais (MANIFESTO C, 2020). Inúmeros artigos foram e serão escritos aqui e no exterior, como o publicado no início de agosto de 2020 pela revista Sight and Sound (BRAZIL'S..., 2020) e o de Darlene Sadlier pela Black Cinema (2021).

A Federação Internacional de Arquivos de Filme (FIAF) escolheu Walter Salles para receber o FIAF Award de 2020, prêmio já conferido a cineastas como Ingmar Bergman, Agnès Varda e Christopher Nolan. O prêmio reconhece a imensidão de sua obra, mas também expressa o apoio da associação à Cinemateca Brasileira, membro histórico da associação. Em outubro do ano passado, belíssimo vídeo produzido pela FIAF com mensagens de apoio de representantes de 32 instituições filiadas foi exibido na Mostra Internacional de Cinema de São Paulo, ocorrida em novembro, e projetada nas paredes externas da instituição em ato de protesto (FIAF, 2020).

Desde o ano passado, a sociedade vem se mobilizando, como é o caso nas sessões ocorridas na Câmara Federal, momento importante de construção de alianças e de formulação de propostas efetivas e concretas para que seja encontrada alguma solução de curto prazo. Manifestações foram organizadas em defesa da Cinemateca pela Associação Paulista de Cineastas (APACI) e pelos movimentos \#SOSCinemateca, \#SOSTrabalhadoresDaCinemateca, \#CinematecaAcesa e Cinemateca Viva. Cineastas, atores e atrizes de diferentes gerações, como Cacá Diegues, Mariana Ximenez, Fernanda Montenegro, Paloma Rocha, Arnaldo Jabor, Walter Salles, Tata Amaral e Jefferson De, dentre muitos outros, denunciam a situação de descaso com o acervo que eles, como parte dos cerca de dois mil depositantes que deixaram seus rolos de filme ou HDs sob a guarda da Cinemateca, construíram.

Por fim, no dia 7 de agosto passado, em frente à Cinemateca Brasileira, grande concentração popular nos fez lembrar que há um ano as portas se encontram fechadas, movimento que encontrou adesão nas cidades do Rio de Janeiro, Curitiba e Brasília.

Como pode ser constatado, não faltaram manifestos, declarações e avisos, sendo o mais recente o dado por Kleber Mendonça Filho no último Festival de Cannes, alertando a comunidade internacional sobre a gravidade do problema.

Infelizmente, a inação federal persistiu e a destruição sobreveio.

9 No dia 23 de agosto deste ano, ocorreu nova audiência pública de conciliação entre os representantes do governo federal e MPF. Nova sessão foi agendada para outubro próximo, mas há expectativa de que contrato emergencial de 90 dias seja assinado para que funcionários especializados possam reestabelecer o mínimo das rotinas de um arquivo audiovisual. 
No final da tarde do dia 29 de julho, um incêndio atingiu as dependências de uma das sedes da Cinemateca Brasileira, situado em terreno de $8 \mathrm{mil} \mathrm{m}^{2}$ próximo à zona cerealista da cidade de São Paulo ${ }^{10}$. Essa unidade vinha recebendo investimentos públicos da instituição desde 2006 para abrigar o Museu do Cinema Brasileiro, o Centro de Referência Audiovisual (CRA) e, fundamentalmente, um novo arquivo de filmes, dado que o da sede principal já se encontrava com a sua capacidade limitada e a intenção era a de expandir o seu acervo. Os dois depósitos climatizados construídos neste espaço tinham capacidade para 25 mil rolos. Foram anos gastos, portanto, com estudos arquitetônicos e técnicos, limpeza dos espaços, adequações, instalações de novas áreas de guarda de acervo, armazenamento de materiais e equipamentos, sempre contando com o apoio de recursos públicos, com o intuito de adaptar o antigo galpão industrial para as finalidades idealizadas.

Esse espaço físico foi destruído pelo fogo, mas, desgraçadamente, as perdas não se restringiram ao edifício e a todo o esforço despendido em sua qualificação. Quatro toneladas de documentação relativa às políticas públicas para o setor cinematográfico no Brasil desapareceram para sempre, assim como equipamentos, que integrariam o futuro museu acima mencionado, e filmes, em quantidade ainda incerta. Também foram consumidos pelo incêndio parte do acervo textual do cineasta Glauber Rocha, além de parcela dos filmes realizados pelos alunos e alunas do Departamento de Cinema, Rádio e Tv da Escola de Comunicações e Artes da USP ${ }^{11}$.

O esforço empreendido por trabalhadores, gestores e toda comunidade cinematográfica para que o padrão de qualidade da Cinemateca Brasileira fosse mantido não resistiu, portanto, ao descaso e ao abandono dispensados pelo governo Bolsonaro à cultura.

O fogo que consome a Amazônia, o Pantanal, o Museu Nacional e a memória audiovisual brasileira demonstra que não estamos diante de coincidências, de fatos isolados, mas de um ataque, projeto articulado de destruição levado a cabo pelas autoridades que governam nosso país (BOCHNER, 2018).

Precisamos demonstrar nossa indignação, união e força, e quando uso a primeira pessoa do plural me refiro a todos os que amam cinema e lutam pela sua história e preservação. Quando Paulo Emilio nos anos 1950 indagava "não há cultura sem perspectiva histórica, e como conhecer a história do cinema se os filmes não foram conservados?” (1981, p. 11), certamente não imaginava o tamanho do desafio que teríamos pela frente.

Este duro golpe não nos desviará da tarefa que se impõe: junto com a sociedade civil, é preciso redobrar nossa luta para que consigamos reverter esta situação desastrosa.

A Cinemateca Brasileira sobreviverá!

\section{REFERÊNCIAS}

BERNADET, Jean-Claude. Asfixia. Outras Palavras, São Paulo, 15 abr. 2019. Blog do Jean-Claude. Disponível em: https://outraspalavras.net/jcbernardet/page/2/. Acesso em: 30 ago. 2020.

BOCHNER, Rosany. Memória fraca e patrimônio queimado. Revista Eletrônica de Comunicação, Informação e Inovação em Saúde, Rio de Janeiro, v. 12, n. 3, p. 244-248, jul.-set. 2018. DOI: https://doi. org/10.29397/reciis.v12i3.1611. Disponível em: https://www.reciis.icict.fiocruz.br/index.php/reciis/article/ view/1611/2220. Acesso em: 26 ago. 2021.

BRASIL. Câmara dos Deputados. A crise na cinemateca brasileira: soluções urgentes. Brasília, DF, 30 jul. 2021. 1 vídeo (48 sec). Disponível em: https://www.camara.leg.br/evento-legislativo/59806/sessao/523225?vid eo=1596119599293. Acesso em: 2 ago. 2021.

10 Como demonstra Calil (2021), se tivéssemos técnicos dentro da instituição os danos, talvez, fossem menores naquele que é o quinto incêndio de sua história.

11 No momento em que escrevo esta nota, não há certeza sobre o que de fato se perdeu com o incêndio. 
BRAZIL'S film archive is facing wipeout. Sight and Sound, Londres, 4 ago. 2020. Features. Disponível em: https://www.bfi.org.uk/sight-and-sound/features/brazils-film-archive-facing-wipeout. Acesso em: 2 ago. 2021.

CALIL, Carlos Augusto. Com 5 incêndios e desprezo do poder público, história da Cinemateca virou pesadelo kafkiano. Folha de S.Paulo, São Paulo, 7 ago. 2021. Ilustríssima. Disponível em: https://www1.folha.uol.com. br/ilustrissima/2021/08/com-5-incendios-e-desprezo-do-poder-publico-historia-da-cinemateca-virou-pesadelokafkiano.shtml. Acesso em: 24 ago. 2021.

CINEMATECA BRASILEIRA. Relatórios Institucionais. São Paulo: A Instituição, [2018?]. Disponível em: http://cinemateca.org.br/institucional/relatorios-institucionais/. Acesso em: 2 ago. 2021.

COMISSÃO de Cultura: situação da Cinemateca Brasileira - 12/04/2021. Brasília, DF: Câmara dos Deputados, [2021]. 1 vídeo (163 min). Publicado pelo canal Câmara dos Deputados. Disponível em: https://www.youtube. com/watch?v=q-kkgpalR11. Acesso em: 2 ago. 2021.

FUNDAÇÃO CULTURAL PALMARES. Retrato do acervo: três décadas de dominação marxista na Fundação Cultural Palmares. Rio de Janeiro: A Fundação, 2021. Disponível em: http://www.palmares.gov.br/wp-content/ uploads/2021/06/cnirc01_liminar_v2_08_07.pdf. Acesso em: 2 ago. 2021.

INTERNATIONAL FEDERATION OF FILM ARCHIVES (FIAF). Video messages celebrating the Cinemateca Brasileira. Bruxelas: FIAF, 2020. Disponível em: https://www.fiafnet.org/pages/News/Cinemateca-Brasileiravideo-messages.html. Acesso em: 2 ago. 2021.

MANIFESTO C. Cinemateca Brasileira pede socorro. [S. I.]: Avaaz, 2020. Disponível em: https://secure. avaaz.org/community_petitions/po/governo_federal_secretaria_especial_de_cultura_sec_cinemateca brasileira_pede_socorrol. Acesso em: 2 ago. 2021.

MORETTIN, Eduardo. O sequestro de nossa memória audiovisual. Jornal da USP, São Paulo, 14 ago. 2020. Disponível em: https://jornal.usp.br/artigos/o-sequestro-de-nossa-memoria-audiovisual/. Acesso em: 14 ago. 2020.

SALLES GOMES, Paulo Emilio. Contra fato há argumento. In: SALLES GOMES, Paulo Emilio. Cinema e política. Seleção de Carlos Augusto Calil. São Paulo: Penguin Classics: Companhia das Letras, 2021. p. 143144.

SALLES GOMES, Paulo Emilio. O congresso de Dubrovnik. In: SALLES GOMES, Paulo Emilio. Crítica de cinema no Suplemento Literário. Rio de Janeiro: Paz e Terra, 1981. v. 1. p. 11-14.

SADLIER, Darlene J. Taking of the Cinemateca Brasileira. Black Camera, Bloomington, v. 12, n. 2, p. 591610, Spring 2021. DOI: https://doi.org/10.2979/blackcamera.12.2.27. Disponível em: https://www.jstor.org/ stable/10.2979/blackcamera.12.2.27. Acesso em: 24 ago. 2021. 